\title{
Study on the Historical Evolution of Chinese System
}

\section{of Voluntary Surrender}

\author{
Defa Kong \\ Qufu People's Court, Qufu 273100, China \\ Tel: 86-537-449-7717Ｅ-mail: kongdf007@163.com
}

\begin{abstract}
The voluntary surrender system of China budded in the Western Zhou Dynasty and matured in the Tang Dynasty, and its concept was first confirmed when the law amendment was implemented in the end period of Qing Dynasty. The 1997 Chinese Criminal Law defined the system of voluntary surrender in detail, and it has been one of special systems in the Chinese legal system. Because the understanding of the historical evolution of the voluntary surrender system is very important for the present jurisdiction and the perfection of the voluntary surrender system, so the course of the voluntary surrender system developing from nothing, becoming better and approaching perfection day by day was unscrambled from the historical view in the article for references.
\end{abstract}

Keywords: Voluntary surrender, Criminal law

\section{The embryo of voluntary surrender system in the period of pre-Qin Dynasty}

This period is the embryo stage of the voluntary surrender system. According to the recordation in the ancient Chinese book of "Shangshu Kanggao", in the Western Zhou Dynasty, someone committed a serious crime, but because he was just the negligent offender or the casual offender, so he might not be sentenced to death penalty. That was the first time in the existing literatures to applied different punishments for criminals according to intentional crime and negligent crime. Of course, this period is only the rudiment of the voluntary surrender system, and the real contents of the voluntary surrender had not occurred.

\section{The system of voluntary surrender in the Qin Dynasty and the Han Dynasty}

According to the recordation of the literatures, since Qin Dynasty, the content of voluntary surrender has appeared in laws, but the word of "Zishou (Chinese transliteration, meanings of voluntary surrender)" had not been appeared, but only the word of "Zichu" or "Zigao" (Chinese transliteration, meanings of voluntary surrender) appeared in laws. The Qin bamboo slips "Questions and Answers of Laws" recorded that "if the official of principal penalty steals above 110 coins surrenders first, he should be punished by penal servitude or money penalty" and "when the women are punished by penal servitude, they run away but surrender, they should be knouted 50 times", and above descriptive records all indicated that if the criminal surrendered, the punishment could be lightened, which is the early laws describing the voluntary surrender system.

Some scholars took the word of "Xian Zigao" as one of appellations of voluntary surrender in some articles, but they all quoted out of context, because the word of "Xian" in the "Xian Zigao" of the Qin bamboo slips "Questions and Answers of Laws" only means that the crime has not been discovered.

The Han Dynasty followed the laws of Qin Dynasty and inherited the voluntary surrender system of Qin dynasty, and it was called by "Zigao (Chinese transliteration, meanings of voluntary surrender)" in the laws of Han Dynasty, and "Zigao" could exempt criminal from criminal responsibility, and its punishment was lighter than the punishment in Qin Dynasty. According to the recordation of the Chinese ancient historical book of "Hanshu, the Biography of Hengshan King", "the son of Hengshan king surrendered first when Hengshan king rebelled, and his punishment was exempted".

The applicable conditions of the voluntary surrender system in Qin Dynasty and Han Dynasty include following aspects. First, the crime had not been discovered, and if the crime has been discovered, the voluntary surrender will not exist, so why the surrender was called as "Zigao". Second, in the complicity crime or the organized crime, the chief criminal could not be exempted from punishment even he surrendered first. Third, the criminal had multiple crimes, only the crime he surrendered could be absolved. Before the Eastern Han Dynasty, the surrendered criminals could be exempted from punishment, but in the Eastern Han Dynasty, some surrendered criminals would be exempted from punishment, and someone only were reduced punishment (Qiao, 2000, P.363). In subsequent dynasties, the federal official always gave priority to one of both and gave assistant to another one. In this period, the "substitute surrender" had not appeared, and the surrender was only limited by the criminal himself. 


\section{The system of voluntary surrender from the Three Kingdoms to the Sui Dynasty}

The word of "Zishou" was appeared in the Three Kingdoms Times to replace the words such as "Zigao (Chinese transliteration, meanings of voluntary surrender)", and it begun into the historical river of the criminal laws. The part of "Zishou (Chinese transliteration, meanings of voluntary surrender)" in the Cao Wei Laws stipulated that the surrendered criminals could be commuted. The historical book of "the Biology of Wangling" recorded that "King of Xuan received Shouchun, and Zhangwu et al all surrendered" (Zhang, 2008, P.158). After that, two Jin dynasties still followed the regulations about commuting surrendered criminals, and some criminals might be exempted from punishment, and the word still used the word of "Zishou". The historical book of "the Biology of Yuchun" recorded that "the emperor exempted Chun's crime because he surrendered" (Cheng, 2006, P.268).

In the period of the Northern and Southern Dynasties, laws of Southern Dynasty including Song Dynasty, Qi Dynasty, Liang Dynasty and Chen Dynasty all specially established the part of voluntary surrender system, and stipulated that the surrendered criminal could be commuted. Taking Chen Dynasty Laws as the example, accruing to the historical book of "the Biology of Huajiao", "the thief commander in chief, Jiexiang, surrendered to the emperor and the emperor exempted his punishment" (Cheng, 2006, 335). Only the Northern Qi Dynasty and the Post-Zhou Dynasty in the Northern Dynasty didn't established the part of the voluntary surrender in the laws, but they all stipulated the contents that the surrendered criminals could be commuted. The Bei Wei Laws still used the word of "Zigao".

Though the Kaihuang Laws of Sui Dynasty had not contained the special part of voluntary surrender, but the contents about the surrender system were still included in it.

\section{The system of voluntary surrender in the Tang Dynasty}

Based on laws of past dynasties, Tang Dynasty further perfected the system of voluntary surrender, and first stipulated the system of voluntary surrender in detail in the history, and its legislation technology could be acclaimed as the peak of perfection, and Tang Dynasty laws about the voluntary surrender system could be called as the classic in the ancient legislations about the voluntary surrender system.

In the "Ming Li Law of Tang Dynasty Laws", the applicable conditions of the voluntary surrender system, the punishments of the voluntary surrender system, the situations which could not be applied in the voluntary surrender system and the equal voluntary surrender system were stipulated in detail.

(1) The applicable conditions of the voluntary surrender system included four points. First, the crime had not been discovered, and if the crime was discovered, even the criminal give himself up to the federal official, he could not be treated as the surrendered criminal. Second, the criminal should inform against him by himself. Third, the voluntary surrender should be honest and complete. Fourth, the voluntary surrender should be made to the federal official.

(2) The punishments after voluntary surrender could be exempted or lightened. There were three situations under which the criminal's responsibilities could be exempted. First, when the crime had not been discovered, the criminal could be exempted for punishments when he surrendered. Second, when the criminal committed above two crimes with different degrees, and if the lighter crime had been discovered but the heavier crime had not been disclosed, the criminal surrendered the heavier crime, so the criminal responsibility of the heavier crime could be exempted, i.e. when one criminal committed multiple crimes and only surrendered the heavier crime, he could be exempted from the punishment of the heavier crime and be run only for the crimes without being surrendered. Third, in the joint offence, when the criminal with lighter crime captured the criminal with heavier crime and surrendered, or one of criminals could capture above half of other criminals and surrendered, he could be exempted for punishment. The premise of these three situations was that the surrender must be honest and complete, or else, the criminal could not be exempted for punishment.

There were four situations to reduce punishment. First, the surrender was not honest and complete, the criminal should be punished by the un-honest and incomplete crime, but the death penalty could be "reduced for one class". Second, when the criminal knew others would disclose his crime and surrendered, the penalty could be "reduced for two classes". Third, when the criminal committed the crime and escaped, and surrendered then, the penalty could be "reduced for two classes". Fourth, "the criminal committed a crime because of another criminal, and criminal surrendered, the penalty could be reduced for two classes, and if another criminal surrendered, his penalty could be reduced for two classes". And when the criminal committed a crime, escaped and returned to the original place, but he didn't surrendered, he should be punished according to the principle of reducing punishment, but this situation was not the situation of surrender, and the opinion which thought that was surrender in some articles was wrong.

(3) There were six situations which should not apply the principle of the surrender punishment. First, the crime was disclosed and the criminal was hunted but he refused to give himself up to the federal official. Second, the crime was to harm others' bodies. Third, the crime was to damage or lose the public things such as chop which could not be compensated by other same things. Fourth, when the criminal committed a crime escaped, and he traversed the pass privately. Fifth, the crime was to rape women. Sixth, the crime was to study the astronomy privately. 
(4) The so-called special surrender was stipulated in Tang Dynasty laws. Tang Dynasty laws also specially stipulated that some situations such as the remaining crime of surrender, the surrender capturing above half other criminals in joint offence, the surrender knowing being disclosed, and some articles called those situations as the special surrenders, but in fact, that opinion was not proper, because the Tang Dynasty laws only listed those situations which were not be applicable usually, and those situations had been described in the former parts of the article.

(5) The systems of "Shou Lu" and "Dai Shou" were stipulated in Tang Dynasty laws. Tang Dynasty laws stipulated that "the criminal stole or fleeced others' property, and he confessed and returned the property, the behavior was same to the surrender for the federal official", which was the system of "Shou Lu". The system of "Shou Lu" was only limited in the crime of property. Some one thought that the behavior the official returned the bribes to the original owner belonged to "Shou Lu", but it was wrong, because "Shou" means confessing, and "Lu" means returning property.

In Tang Dynasty laws, after the criminal committed a crime, his families who could hid him according to the laws replaced him and disclosed the crime to the federal official, the punishment to the criminal should refer to the principle of surrender, which was the system of "Dai Shou", and the premise condition of "Dai Shou" must be implemented by the families who had right to hid the criminal according to the laws. So the systems of "Shou Lu" and "Dai Shou" should be called as the special surrender system more properly.

(6) The system of "Zi Xin" was stipulated in Tang Dynasty laws. If the crime had be disclosed, or perceived by the federal official, he went to confess the crime, which was called as "Zi Xin", not "surrender".

(7) The officials' surrender was specially stipulated in Tang Dynasty laws, but the surrender was only limited in the situation that the official committed a crime non-intentionally.

\section{The system of voluntary surrender from the Song Dynasty to the Yuan Dynasty}

\subsection{The system in the Song Dynasty}

The laws of Song Dynasty inherited from the laws of Tang Dynasty, and the surrendered criminals were exempted from punishments, but some following new contents were added in the voluntary surrender system.

(1) In the "Ming Li Law" of "the Criminal Law of Song Dynasty", "when the criminal committed a crime which was not disclosed, and surrendered, the criminal could be exempted from punishment. And though the lighter crime was disclosed, but the heavier crime was not disclosed, and the criminal surrendered his heavier crime, and his heavier crime could be exempted from punishment. And the families who had the rights according to the laws could replace the criminal to surrender, and the criminal could be exempted from punishments". Based on the laws of Tang Dynasty, the laws of Song Dynasty further stipulated how to surrender when the lighter crime was disclosed, but the surrender was limited, i.e. when the lighter crime was disclosed and the criminal surrendered his heavier crime, the responsibility of the heavier crime could be exempted.

(2) The confession was accepted into the category of the voluntary surrender system. The content about the confession inherited from Tang Dynasty laws, and changed little.

(3) The articles that the surrendered criminal could not be exempted from punishment. According to the "Criminal Law One" of "Records 152nd" of "the History of Song Dynasty", "if the official died or left his post and his underlings escaped, the underlings could not apply the surrender system."

In addition, the article that "the crime was disclosed or undisclosed and the criminal surrendered" existed in "the Criminal Law of Song Dynasty", how to explain the "disclosed"? Some scholars thought that the laws of Song Dynasty inherited the laws of Tang Dynasty which stipulated that "the crime was undisclosed", so the "disclosed" in "the Criminal Law of Song Dynasty" was only the derivative word (Cheng, 2006, P.335). Except of the Song Dynasty, the word of "disclosed" didn't exist, so the explanation may be the most reasonable one.

\subsection{The system in the Liao Dynasty and the Western Xia Dynasty}

The Liao Dynasty and the Western Xia Dynasty were the countries established by minorities, and they were the important minority regimes in the North, and their criminal laws absorbed the abstract culture of Han and also stipulated the system of voluntary surrender.

The criminal laws of Liao Dynasty stipulated that the surrendered criminal could be exempted or reduced from punishment, and according to the "the Records of Criminal laws" of "the History of Liao Dynasty", "the official in Huiyong escaped and surrendered, and his crime was exempted". But the usage of the voluntary surrender was random, for example, the attendants of the emperor escaped with the wife of the king of Qi, he surrendered in the sequel, but he was still killed by the emperor ("Records of Criminal Law Thirty" of "the History of Liao Dynasty", Zhonghua Book Company Press, Oct, 1974).

The voluntary surrender system was stipulated in detail in the Western Xia Dynasty, and the correlative regulations not only included the detailed extent of the reduced punishment, but decided the degree of the reduced punishment 
according to the losses retrieved by the surrender. "Thieves or robber returned the stolen things, and when $2 / 5$ of these stolen things were returned, the punishment of the surrendered criminal was reduced for two classes, and the punishment of the accessories was reduced for one class, and when $3 / 5$ of these stolen things were returned, the punishment of the surrendered criminal was reduced for three classes, and the punishment of the accessories was reduced for two classes (Yang, 2003)". This change was the advancement of the history, and it was the new development of the voluntary surrender system, and it could really exert the function and value of the voluntary surrender system, and it could be used for references to perfect the present system of voluntary surrender.

\subsection{The system in the Yuan Dynasty}

The laws of Yuan Dynasty "inherited the classics of Tang Dynasty and Song Dynasty, and integrated with laws of Han", and mixed with the culture and legal system of Mongolia and the traditional legal cultures of central plains. It also stipulated that the surrendered criminal could be exempted or reduced from punishment, and totally speaking, the voluntary surrender system had not been developed largely, but there were still following prominent advantages.

(1) The families were allowed to replace the criminal to surrender. Generally, the surrender should be performed by the criminal himself, and if he was sick, his families could replace him to surrender, but the false surrender was strictly forbidden. In the "Records of Criminal Law One" of "the History of Yuan Dynasty", "counterfeit surrender was forbidden, and if the criminal is sick, his families could be allowed to surrender". In the history, the families of the criminal were allowed to replace the criminal to surrender in the writing laws.

(2) When officials took bribes, they were not allowed to surrender. Not only the officials could not apply the surrender system, but the federal official who accepted the surrendered official should assume the criminal responsibility. In the "Records of Criminal Law One" of "the History of Yuan Dynasty", "the officials take bribes, they should not apply the surrender system, and the superior official who accepts the surrendered official will be punished".

(3) The surrender was limited by the time. In the "Records of Criminal Law Two" of "the History of Yuan Dynasty", the criminal surrendered after a long time, the surrender was not effective, but the concrete time limit such as one year or half year was not stipulated.

(4) The system of "Shou Fu (Chinese transliteration, meanings of voluntary surrender)" occurred. The system of "Shou Fu" rooted from "Shou Lu" in Tang Dynasty, and some scholars thought that the word occurred in the Ming Dynasty and Qing Dynasty, but the opinion was wrong, and the word first occurred in Yuan Dynasty. "Shou Fu" could be reduced from punishment, and in the "Records of Criminal Law Two" of "the History of Yuan Dynasty", "the thieves surrendered because the victim cross-examined them and they didn't return the stolen things, their punishments were reduced for two classes, and tattooed characters on the skin (an ancient corporal punishment)". Here, "Shou Fu" didn't require that the stolen things were returned completely to owners, and the criminals were punished according to the returning situation when they returned the stolen things.

\section{The system of voluntary surrender in the Ming Dynasty and the Qing Dynasty}

The article of "voluntary surrender system" was established in the "Ming Li Law" of "Laws of Ming Dynasty", and the laws basically inherited former dynasties and only the concrete contents were added or reduced. For example, in the "Ming Li Law", "the criminal perverted the law and didn't pervert the stolen things, and he regretted and returned the things to the owner, and he could be treated as the surrendered criminal, and his punishment could be exempted. And if he knew someone would disclose he and he returned the stolen things to the owner, his punishment could be reduced for two classes". Above content was exclusive in laws of Ming Dynasty, and total speaking, the contents about the voluntary surrender system changed little in laws of Ming Dynastic.

The "Ming Li Law" of "Laws of Qing Dynasty" not only stipulated the voluntary surrender system, but strictly distinguished the reduced punishment of the surrendered criminal, the undisclosed surrendered criminal, and the disclosed "Zi Xin" criminal, and the conditions of the surrender, and the treatment of the incomplete surrender (Zhang, 1993, P.180). Comparing with former dynasties, the range and time limit of the surrender punishment were extended, and in the "Du Pu Ze Li" in period of Kangxi Emperor, "the families in banner-men escaped in one year and surrendered, and their punishments could be exempted (the article of "Escaper Surrender" of "Volume A of Du Pu Ze Li")". For the criminals who captured the criminals in the same case and surrendered to the federal official, the reduced punishment degree and extent all exceeded former dynasties, "the criminals who could regretted their crimes and captured other criminals and surrendered to the federal official, and if they belonged to the harming-person criminals, their punishments were reduced for class one, or else, they should be exempted from punishment by the laws (Thieves of Criminal Law of Qing Dynasty Laws)".

In the beginning period of Qing Dynasty, the disposal principle of the surrendered criminal was extended to the forbiddance of opium, which was the measure aiming at the situation that the opium poisoned the government and people in the period of Daoguang Emperor. 
In the law emendations at the end of Qing Dynasty, Qing Dynasty could "refer to laws of various countries", and it first definitely put forward the concept of "Zi Shou" in the criminal laws in the history of China. In the "New Criminal Laws of Qing Dynasty", "Zi Shou" was defined as the "the crime has not been disclosed, and the criminal surrenders to the federal official". At the same time, the voluntary systems about the conspiring offender and the preparing offender were also stipulated.

\section{The system of voluntary surrender in the Republican China}

After the Republican China replaced the Qing Dynasty, because the political situation was not stable, and the rights were from various governments, so the contents about the voluntary surrender were not consistent.

In the "Implementation Regulations of Criminal Laws" enacted by Nanjing Kuomintang Government in 1928, the content of the voluntary surrender didn't be contained. In the "Criminal Laws" of 1934, the voluntary surrender system had begun to occur, "for the criminal whose crime has not been disclosed and who obeys the judgment, the punishment should be reduced, but if there is the special regulation, the punishment is performed by the special regulation (Criminal Laws of Republican China enacted by Nanjing Kuomintang Government in 1934, P. 62)". The conditions of voluntary surrender were that the crime had not been disclosed and the criminal obeyed the judgment, and the criminal's punishment was reduced or exempted in special regulations. In the division regulations of Criminal Laws also stipulated the voluntary surrender system, for example, in the article 172, "for the surrendered criminals who committed the perjury crime and the false charging crime, their punishments could be reduced or exempted". The Criminal Laws of Republican China was modified several times, but the contents of the voluntary surrender changed little, and only the specific words were added or deleted. The modified Criminal Laws of Republican China has been used in Taiwan area up to now. In other special decrees enacted by Nanjing Kuomintang Government, the content about the voluntary surrender was always contained, for example, in the decree about punishing traitors, "the criminals who committed the crime are punished by the traitor surrender decree (The Emendation of the Decree of Publishing Traitors, enacted by Nanjing Kuomintang Government, article 18, 1938)".

In this period, the content of voluntary surrender also occurred in the criminal laws enacted by the Manchukuo, for example, in the urgency punishment law, "the criminals who committed the crime and surrendered before being disclosed are reduced from their punishments. For the autonomous-complaint crime, the punishment of the criminal is same to the above regulation (Criminal Laws, enacted by Manchukuo government, article 57, 1937)".

The content of voluntary surrender in the criminal laws enacted by other governments except for Nanjing Kuomintang Government all didn't exert the corresponding functions because the governments were illegal or those governments only presented a false picture of peace and legal system.

\section{The system of voluntary surrender from 1949 to this day}

Before PRC was established, most of the criminal legislations of the revolutionary base areas leaded by the CPC stipulated the criminal policy of "leniency toward those who confess their crimes", and the regulations about the voluntary surrender system, for example, in the special decree enacted by the Shandong anti-Japanese base areas, "traitors who surrenders to the judicatory government or the democracy government before he is arrested, should be reduced or exempted for punishments (Shandong Provisional Regulation for Traitor Surrender, enacted by the Shandong Provincial Government, Article 2, 1945)". The content about the voluntary surrender system almost all existed in the criminal special decrees or regulations by various revolutionary base areas, and the difference was little, and the quantity of the legal regulations was excessive.

After PRC was established since 1949, through using the foreign and ancient legislation practices of the voluntary surrender system for references, the voluntary surrender system has experienced the long term period from forming roughly to gradually developing and perfecting. There are four legal regulations about the voluntary surrender system, i.e. the old criminal laws of 1979, the united explanation of 1984, the new criminal laws of 1997 and the judicial interpretation of 1998.

The 1979 Criminal Law stipulated that "the criminal who commits a crime and surrenders voluntarily may be given a lighter punishment" in the "voluntary surrender" part of the chapter of "the concrete utilization of criminal punishment". In addition, the 1979 Criminal Law also stipulated that the criminal with lighter crime who surrenders might be given a lighter punishment or exemption from punishment, and though his crime was heavier but he made contributions, he could also obtain a lighter punishment or exemption from punishment. The limitation of the voluntary surrender system in the 1979 Criminal Law was that the defined articles about the voluntary surrender system were deficient. But first, the 1979 Criminal Law broken the limitation of "the crime is not disclosed", i.e. the whether the crime was disclosed or undisclosed, the voluntary surrender could come into existence, and second, the 1979 Criminal Law associated the voluntary surrender system with the "making contributions", and extended the applicable range of the voluntary surrender, which more made for criminals' regrets and save the judicial resources. The 1979 Criminal Law was substituted by the new Criminal Law of 1997. 
In 1984, the Supreme People's Court and the Supreme People's Procuratorate issued the "Explanations of the Concrete Legal Applications about How to Process the Voluntary Surrender and Correlative Questions" with Chinese Ministry of Public Security, which compensated the deficiencies of the 1997 Criminal Law. The Explanation definitely stipulated many concrete judicial applications such as "how to cognize the voluntary surrender", "how to punish the voluntary surrender", "how to treat the case bringing families or relatives to justice" and "how to treat the contribution", and the Explanation further enriched and developed the system of voluntary surrender. The Explanation listed the voluntary surrender cognizance, stipulated the applicable conditions of the voluntary surrender such as subjectively giving himself up the police, explaining the crime according to the facts and accepting the trial and judgment subjectively. For the situations that the crime had not been disclosed, or though the crime was disclosed but the criminal "has not been interrogated or adopted by compulsion measures", the voluntary surrender of the criminal could come into existence, which further extended the system of the voluntary surrender based on the 1979 Criminal Law. The crime confession was required that the main crime should be confessed, which was different to the part crime which should be given a lighter punishment or exemption of punishment, and in the joint offence, the criminal should also confess other criminals in the same case, and the principal "must disclose the crime of other criminals in the same case", or else, the voluntary surrender could not come into existence. For the subjective giving criminal himself up to the police, the situations that the relatives brought the families or friends to justice also belonged to the voluntary surrender. The making-contribution was divided into the common making-contribution and the major making-contribution, and the confession policy was also stipulated in the Explanation. At present, the Explanation is still being applied.

In March of 1997, the 1997 Criminal Law replaced the 1979 Criminal Law and perfected the system of voluntary surrender. In the chapter of "the Concrete Utilization of Punishment", the part of "Voluntary Surrender and Making Contributions" definitely confirmed the definition of the voluntary surrender secondly following the "New Criminal Law of Qing Dynasty", i.e. "the criminal who commits a crime and surrenders subjectively confesses his crime according to the facts, and the voluntary surrender comes into existence", which was the common voluntary surrender. The punishments about the surrendered criminal in 1997 Criminal Law were same to the punishments in the 1979 Criminal Law, and the extent of punishment was looser. In addition, in the new criminal law, "if the criminal suspect who is adopted by compulsive measure, the accused person and the criminal who is serving a sentence confess other crimes that the judicial department has not known according to the facts, the voluntary surrender comes into existence", which was called as the special voluntary surrender, quasi-voluntary surrender, or the voluntary surrender of remaining crime. The voluntary surrender in the special provisions of criminal law was generally called as the special voluntary surrender. The 1997 Criminal Law had not contained the regulation about confession.

The "Explanations of Several Application Questions about Criminal Case of Voluntary Surrender and Making Contributions" enacted by the Supreme People's Court stipulated the regulations about the honestly confession and how to cognize the voluntary surrender to justice, which was the concrete complement of the 1997 Criminal Law.

From the Western Zhou Dynasty to this day, the system of voluntary surrender was continually substantiated and developed, but comparing with foreign legal systems, the present system of voluntary surrender of China still needs to be further perfected, for example, further confirming the criminal punishment extents. In the article, only the evolvement of the system of voluntary surrender was briefly narrated, and the concrete contents of the voluntary surrender system in each dynasty were not introduced.

\section{References}

Cheng, Shude. (2006). Textural Research of Nine Dynasties'Laws. Taibei: Zhonghua Book Company. Nov, 2006. P.268 $\& 335$.

Qiao, Wei. (2000). Qiaowei Corpus · Volume Two · History of Chinese Legal System. Jinan: Shandong University Press. P.363.

Yang, Jitang. (2003). Western Xia Dynasty Culture in Laws: Research of Western Xia "Tian Sheng Gai Jiu Xin Ding Lv Ling”. Beijing: Law Press China. Dec, 2003.

Zhang, Jinjian. (2008). Outline of History of Chinese Law. Taibei: Taiwan Zhongzheng Book Company. P. 157 \& P.158.

Zhang, Jinpan. (1993). History of Laws in Qing Dynasty. Beijing: Law Press China. Oct, 1993. P.180. 